\title{
Morpholinolysis of Esters Analogous to Flutamide in 90\% Methanol-water
}

\author{
Nada. M. Youssef ${ }^{1}$, Shawky Elshazly ${ }^{1,2}$, Ezzat. A. Hamed ${ }^{1,2}$ \\ ${ }^{1}$ Department of Chemistry, Faculty of Science, Beirut Arab University, Beirut, Lebanon. \\ ${ }^{2}$ Department of Chemistry, Faculty of Science, Alexandria University,Ibrahimia 21321, P.O. Box 426, Alexandria, \\ Egypt. \\ Correspondence: Nada. M. Youssef, Department of Chemistry, Faculty of Science, Beirut Arab University, \\ Beirut, Lebanon. E-mail: nadayoussefjnainati@hotmail.com
}

Received: December 21, 2014 Accepted: January 16, 2015 Online Published: March 3, 2015

doi:10.5539/ijc.v7n1p111 URL: http://dx.doi.org/10.5539/ijc.v7n1p111

\begin{abstract}
The kinetics of the reaction of ester analogous to flutamide namely nitrophenyl acetate, butyrate and isobutryrate with morpholine in 90\%Methanol-water is measured spectrophotometrically and show second order rate constants. The second order rate constants as well as activation parameters were calculated at $25-45^{\circ} \mathrm{C}$. The mechanism of acyl-oxgen fission pass through stepwise mechanism and the position of slow step depends on the nature and position of substituent in the ester group as well as the chain structure of the non-leaving group. The second order rate constants, activation parameters and the correlation between $\log \mathrm{k}_{\mathrm{A}(25)}$ versus $\log \mathrm{k}_{\mathrm{A}(45)}$ can decide the position of the slow step.
\end{abstract}

Keywords: Flutamide analogous, acyl-oxygen fission, uncatalyzed reaction, stepwise mechanism, concerted mechanism, n-butyrate, isobutyrate, Morpholine, 90\% Methanol-water.

\section{Introduction}

Esters have been studied extensively due to its important role in biological, chemical, environmental industrial processes and many natural molecules (Ibrahim, El-atawy, El-Sadany \& Hamed, 2011)

Reactions of amines with carbonyl compounds have intensively been investigated due to importance in chemistry as well as in biological processes (Um, Lee. E-J., \& Lee. J-P, 2002) and the reaction mechanism has been fairly well known (Lee. J-P, Yoon \& Um, 1999).

The reaction mechanism for aminolysis of carboxylic esters has been suggested to proceed through an addition intermediate in which the rate determining-step (RDS) is dependent on the basicity of the leaving group and the nucleophilic amine (Um et al. 2002). Linear free energy relationship such as Brønsted or Hammett equation has been the most popular probe to investigate the reaction mechanism

(Bernasconi, 1986). Nonlinear Brønsted-type plot has often been observed for aminolysis of carboxylic esters with a good leaving group, and has been attributed to a change in the RDS of a stepwise mechanism upon changing the basicity of the leaving group or the nucleophilic amines (Um et al. 2002).

It has long been known that either the acyl-oxygen bond or aryl-oxygen bond of phenyl esters can be cleaved depending on: (i) the structure of the ester, (ii) the nature of reagent (iii) the basicity of the leaving group anion compared to that of the attacking nucleophile (iv) the nature of substituent in the aryl or the acyl group containing the ester (Ibrahim, El-atawy, El-Sadany \& Hamed, 2013) and (v) the relative "hardness" and "softness" of the reaction site and reagent. Competition between the two electrophillic centers in the ester substrate is well documented for reactions of nitrophenylsulfonates, sulfates and phosphates with nucleophiles (Feuer, Patai, 1969 \& Buncel et al., 1975 \& Kirby, Jencks, 1965). On the other hand, most carboxylic esters undergo acyl-oxygen scission(Feuer et al., 1969 \& Kirby et al., 1965) partial Ar-oxygen scission was also reported attributable to the strong activation of the 1-position (ipso) of the phenolic group by the nitro groups (Guanti et al., 1975).

As a continuation of our work in the field of nucleophilic aryl and acyl reactions, (Hamed, $1997 \& 2011$; Hamed, El-Bardan, Saad, Gohar \& Hassan 1997; El-Hegazy, Abdel-Fattah, Hamed \& Sharaf, 2000; Fathalla, Kassem \& 
Hamed, 2009; Khattab, Hamed, Albericio, El-Faham, 2010) we addressed kinetic studies of the leaving group ability of phenol containing one or two electron withdrawing groups. Morpholine (Mo) was selected as nucleophile because it possess a comparable $\mathrm{pKa}$ value to those reported for many acids.

We studied the mechanism for the reaction of the esters 1-9 (Figure1) with Mo in 90\% methanol-water to examine (i) the mode of scission whether is the CO-O or/and Ar-O bond scission pathways, (ii) The effect of nitro group position on rate and mechanism, and (iii) The effect of introduction of trifluoromethyl group $\left(-\mathrm{CF}_{3}\right)$ in addition to the nitro group.<smiles>CC(=O)Oc1ccc([N+](=O)[O-])cc1</smiles>

(1)<smiles>CCCC(=O)Oc1ccc([N+](=O)[O-])cc1</smiles>

(3)<smiles>CCCC(=O)Oc1ccccc1[N+](=O)[O-]</smiles>

(5)<smiles>CCCC(=O)Oc1ccc([N+](=O)[O-])c(C(F)(F)F)c1</smiles>

(7)<smiles>CC(=O)Oc1ccccc1[N+](=O)[O-]</smiles>

(2)<smiles>CC(C)C(=O)Oc1ccc([N+](=O)[O-])cc1</smiles>

(4)<smiles>CC(C)C(=O)Oc1ccccc1[N+](=O)[O-]</smiles>

(6)<smiles>CC(C)C(=O)Oc1ccc([N+](=O)[O-])c(C(F)(F)F)c1</smiles><smiles>CCCC(=O)OCc1ccc(C(F)(F)F)cc1[N+](=O)[O-]</smiles>

Figure 1. (Esters 1-9)

Ester (8) is analogues to flutamide (4-nitro-3-trifluoromethyl-isobutilanilide: Figure 2), but with an oxygen atom replacing nitrogen atom while the other esters differ from flutamide in the position of substitutent in the aromatic ring and the structure of the ester group -OR. Flutamide seems to have antiandrogenic specificity only in genitalia organs androgen-dependent, and its therapeutic use is in prostatic cancer (Brogden, Clissold, 1989). 


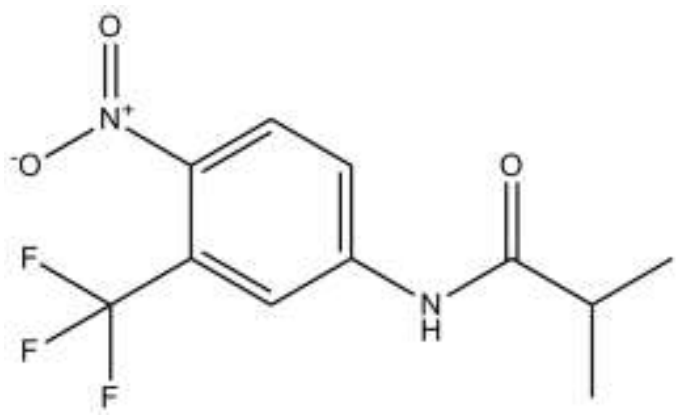

Figure 2. Flutamide

After human oral administration flutamide is quickly metabolized, producing about ten metabolites, mainly 2-hydroxyflutamide and 3-trifluoromethyl-4-nitroaniline Figures 3 \& 4 (Jonler, Riehmann, Bruskewitz, 1994).<smiles>CC(C)(O)C(=O)Nc1ccc([N+](=O)[O-])c(C(F)(F)F)c1</smiles>

Figure 3. (2-hydroxyflutamide).<smiles>Nc1ccc([N+](=O)[O-])c(C(F)(F)F)c1</smiles>

Figure 4. (4-Nitro-3-trifluoromethyl aniline).

\section{Material and Methods}

\subsection{Materials}

Methanol was obtained from Sigma Aldrich $>99.99 \%$ and were used without further purification. Morpholine was obtained from Sigma Aldrich and used without distillation. The UV spectra were carried out on a V-730, UV-VIS spectrophotometer. Infrared spectra (IR) were recorded on a Perkin-Elmer 1600 series Fourier Transform instrument as $\mathrm{KBr}$ pellets. Nuclear Magnetic resonance spectra $\left({ }^{1} \mathrm{H}\right.$ NMR spectra) were recorded on a JOEL $300 \mathrm{MHz}$ spectrometer with chemical shift values reported in $\delta$ units (ppm) relative to an internal standard. Follow-up of the reactions and checks of the purity of the compounds was done by TLC on silica gel-protected aluminum sheets (Type 60 GF254, Merck) and the spots were detected by exposure to UV-lamp at $\lambda=254 \mathrm{~nm}$ for a few seconds.

\subsection{Synthesis of the Starting Materials}

\subsubsection{Synthesis of 4-nitro-2-trifluoromethylphenol}

A round bottom flask with a magnetic stirring bar was charged with 1-chloro-4-nitro-2- trifluoromethylbenzene (414mg, 2mmol) in ethanol. The reaction mixture was stirred with $\mathrm{NaOH}(1: 2)$ for 1 hour at room temperature, and then heated for 24 hours then allowed to cool to room temperature, diluted with $4-5 \mathrm{~mL}$ of ethyl acetate and water, filtered and washed with $10-20 \mathrm{~mL}$ of ethyl acetate. The combined organic extracts were dried over $\mathrm{Na}_{2} \mathrm{SO}_{4}$, filtered and concentrated under vacuum. The resulting residue was purified by column chromatography on silica gel (petroleum ether/ethylacetate1:1) to provide the desired product as a yellow solid $(178 \mathrm{mg}$, Yield = $43 \%)$.

\subsubsection{General Synthesis for the Preparation of esters (1-9)}

Acid chlorides namely acetyl chloride, n-butyl chloride and isobutyl chloride (10mmol) were added to a mixture of phenols namely 2-nitrophenol, 4-nitrophenol, 4-nitro-3-trifluoromethyl phenol and 4-nitro-2-trifluoromethyl phenol, (10mmol) and $\mathrm{Et}_{3} \mathrm{~N}(2.8 \mathrm{~mL}, 20 \mathrm{mmol})$ in $\mathrm{CH}_{2} \mathrm{Cl}_{2}(5 \mathrm{~mL})$ as solvent. The reaction mixture was stirred for 3 hours at room temperature and then washed with saturated $\mathrm{NaHCO}_{3}(2 \times 10 \mathrm{~mL})$, saturated $\mathrm{NaCl}(2 \times 10 \mathrm{~mL})$ and $\mathrm{H}_{2} \mathrm{O}(2 \times 1 \mathrm{~mL})$. The organic layer was dried over anhydrous $\mathrm{Na}_{2} \mathrm{SO}_{4}$ and filtered and the solvent was removed under vacuum. The crude product was purified by column chromatography (ethylacetate/hexane) as 
pale yellow liquids except for ester (9) which obtained as yellow solid. The spectral data of the prepared compounds are given below.

4-nitrophenyl n-butryrate (3): Pale yellow oil, IR $\left(\mathrm{KBr}, \mathrm{v}_{\max }, \mathrm{cm}^{-1}\right): 1765(\mathrm{C}=\mathrm{O}), 1524\left(\right.$ asym $\left.-\mathrm{NO}_{2}\right), 1348$ ( sym- $\left.\mathrm{NO}_{2}\right) .{ }^{1} \mathrm{HNMR}\left(\mathrm{CH}_{3} \mathrm{OD}\right)$ dppm :0.98-1.03 (H-4, 3H,t), 1.69-1.81 (H-3, 2H, m), 2.53-2.58 (H-2, 2H, t). ArH : 7.21-7.28 (H2',6', 2H, d), 8.17-8.22 (H3',5', 2H, d).

4-nitrophenyl isobutryrate (4): Pale yellow oil, $\mathrm{IR}\left(\mathrm{KBr}, \mathrm{v}_{\max }, \mathrm{cm}^{-1}\right)$ : $1754(\mathrm{C}=\mathrm{O}), 1530\left(\right.$ asym $\left.-\mathrm{NO}_{2}\right), 1346$ (sym- $\left.\mathrm{NO}_{2}\right) .{ }^{1} \mathrm{HNMR}\left(\mathrm{CD}_{3} \mathrm{OD}\right) \delta$ ppm:1.58 $(\mathrm{H}-3,6 \mathrm{H}, \mathrm{d}), 3.25(\mathrm{H}-2,1 \mathrm{H}, \quad \mathrm{m}) . \mathrm{ArH}: 7.71-7.75\left(\mathrm{H} 22^{\prime}, 6{ }^{\prime}, 2 \mathrm{H}, \mathrm{d}\right)$, 8.66-8.69 (H3',5', 2H, d).

2-nitrophenyl n-butryrate (5): Pale yellow oil, IR ( $\left.\mathrm{KBr}, \mathrm{v}_{\max }, \mathrm{cm}^{-1}\right): 1771(\mathrm{C}=\mathrm{O}), 1532$ (asym $\left.-\mathrm{NO}_{2}\right), 1352$ ( sym- $\left.\mathrm{NO}_{2}\right)$. ${ }^{1} \mathrm{HNMR}\left(\mathrm{CD}_{3} \mathrm{OD}\right) \delta$ ppm:0.98-1.06 ( H-4, 3H,t), 1.66-1.78 $(\mathrm{H}-3,2 \mathrm{H}, \mathrm{m}), 2.55-2.6(\mathrm{H}-2,2 \mathrm{H}, \quad \mathrm{t})$. ArH : 7.25-7.28 (H-6', 1H, d), 7.38-7.44 ( H-5', 1H, t), 7.65-7.71 ( H-4', 1H, t), 8.03-8.05 ( H-3', 1H, d).

2-nitrophenyl isobutryrate(6): Pale yellow oil, IR $\left(\mathrm{KBr}, \mathrm{v}_{\max }, \mathrm{cm}^{-1}\right): 1768(\mathrm{C}=\mathrm{O}), 1532$ (asym $\left.-\mathrm{NO}_{2}\right), 1352$ $\left(\right.$ sym- $\left.\mathrm{NO}_{2}\right) .{ }^{1} \mathrm{HNMR}\left(\mathrm{CD}_{3} \mathrm{OD}\right) \delta \mathrm{ppm}: 1.60-1.71(\mathrm{H}-3,6 \mathrm{H}, \mathrm{d}), 3.18-3.3(\mathrm{H}-2,1 \mathrm{H}, \quad \mathrm{m})$. ArH : $\quad$ 7.66-7.67 ( H-6', 1H, d), 7.83 ( H-5', 1H, t), 8.10 ( H-4', 1 H, t), 8.44-8.47 (H-3', 1 H, d).

4-nitro-3-trifluoromethylphenyl n-butryrate (7): Pale yellow oil, IR $\left(\mathrm{KBr}, \mathrm{v}_{\max }, \mathrm{cm}^{-1}\right): 1772(\mathrm{C}=\mathrm{O}), 1544$ (asym $\left.-\mathrm{NO}_{2}\right), 1358$ ( sym-NO $\left.{ }_{2}\right) .{ }^{1} \mathrm{HNMR}\left(\mathrm{CD}_{3} \mathrm{OD}\right) \delta$ ppm: 1.038-1.31 $(\mathrm{H}-4,3 \mathrm{H}, \mathrm{t}), 1.74-1.87(\mathrm{H}-3,2 \mathrm{H}, \mathrm{m})$, 2.62-2.64 (H-2, 2H,t). ArH : 7.491-7.528 ( H-6', $1 \mathrm{H}, \mathrm{dd}, \mathrm{J}=2.4,2.1 \& 8.85 \mathrm{~Hz}) .7 .589-7.596(\mathrm{H}-2$ ', $1 \mathrm{H}, \mathrm{s}, \mathrm{J}=$ $2.1 \mathrm{~Hz}), 7.972-8.001(\mathrm{H}-5$ ', $1 \mathrm{H}, \mathrm{d}, \mathrm{J}=8.7 \mathrm{~Hz}$ ).

4-nitro-3-trifluoromethylphenyl isobutryrate (8): Pale yellow oil, IR $\left(\mathrm{KBr}, \mathrm{v}_{\max }, \mathrm{cm}^{-1}\right): 1769(\mathrm{C}=\mathrm{O}), 1544$ (asym $\left.-\mathrm{NO}_{2}\right), 1358\left(\right.$ sym- $\left.\mathrm{NO}_{2}\right) .{ }^{1} \mathrm{HNMR}\left(\mathrm{CD}_{3} \mathrm{OD}\right) \delta \mathrm{ppm}: 1.34-1.36(\mathrm{H}-3,6 \mathrm{H}, \mathrm{d}), 2.8-2.94(\mathrm{H}-2,1 \mathrm{H}, \mathrm{m}) . \mathrm{ArH}$ : 7.484-7.521 ( H-6', $1 \mathrm{H}, \mathrm{dd}, \mathrm{J}=2.4,2.4 \& 8.7 \mathrm{~Hz}$ ).7.581-7.589 ( H-2', 1H, d, J = 2.4Hz), 7.97-8.006 ( H-5', 1H, d, $\mathrm{J}=9 \mathrm{~Hz})$.

2-nitro-4-trifluoromethylphenyl n-butryrate (9): melting point $=68.5-70^{\circ} \mathrm{C}, \mathrm{IR}\left(\mathrm{KBr}, \mathrm{v}_{\max }, \mathrm{cm}^{-1}\right): 1780(\mathrm{C}=\mathrm{O})$, 1544 (asym - $\left.\mathrm{NO}_{2}\right), 1348$ ( sym-NO ${ }_{2}$ ). ${ }^{1} \mathrm{HNMR}\left(\mathrm{CD}_{3} \mathrm{OD}\right) \delta \mathrm{ppm}: 1.506-1.572(\mathrm{H}-4,3 \mathrm{H}, \mathrm{m}), 1.596-1.706(\mathrm{H}-3$, $2 \mathrm{H}, \mathrm{m}), 4.237-4.307(\mathrm{H}-2,2 \mathrm{H}, \mathrm{t})$. ArH : 7.173-7.203 ( H-6', 1H, d, J = 9Hz), 7.768-7.805 ( H-5', 1H, dd, J = $2.4,2.4,9 \mathrm{~Hz}), 8.117-8.123(\mathrm{H}-3$ ', $1 \mathrm{H}, \mathrm{dd}, \mathrm{J}=1.8,1.6,10.5 \mathrm{~Hz})$.

\subsubsection{Kinetic Measurements}

The kinetics of compounds ( 1 to 9) with morpholine was measured spectrophotometrically using a V-730 spectrophotometer. The kinetic runs were carried out at five temperatures $\left(25-45^{\circ} \mathrm{C}\right)$ in $90 \%$ Methanol-water. The rates were measured spectrophotometrically by following the formation of aryloxide anions namely 2-nitrophenoxide at $\lambda=410 \mathrm{~nm}, 4$-nitro-phenoxide at $\lambda=400 \mathrm{~nm}, 4$-nitro-3-trifluoromethylphenoxide at $\lambda=390 \mathrm{~nm}$ and 2-nitro-4-trifluoromethylphenoxide at $\lambda=395 \mathrm{~nm}$. All reactions were carried out under pseudo-first-order conditions, with various concentrations of morpholine $\left(10^{-3}-3 \times 10^{-1} \mathrm{~mol} \times \mathrm{dm}^{-3}\right)$ and final concentration of esters used $\left(10^{-4} \mathrm{~mol} \times \mathrm{dm}-3\right)$. The pseudo first-order rate constants $\mathrm{k}_{\mathrm{obs}}$ were estimated by applying equation 1

$$
\log \left(A_{t}-A_{\infty}\right)=\frac{-k_{o b s} \times t}{2.303}+\log \left(A_{0}-A_{\infty}\right)
$$

Where $\mathrm{A}_{0}, \mathrm{~A}_{\mathrm{t}}$ and $\mathrm{A}_{\infty}$ are the values of absorbance at zero time, time $\mathrm{t}$, and at the end of the reaction, respectively. The $A_{\infty}$ for each run was taken as the experimentally determined values, and $\mathrm{k}_{\mathrm{obs}}$ is the pseudo-first-order rate constant.

\section{Results and Discussion}

\subsection{Preparation of Starting Compounds 1 to 9}

Reaction (1) of phenol derivatives (10-13) with acetyl, butyryl and isobutyryl chlorides afforded the rapid formation of esters (1 to 9) in good yields as a pale yellow oily products except for ester (9) which was obtained as yellow solid (Reaction 1).

The molecular structure of 4-nitrophenyl acetate (1) and 2-nitrophenyl acetate (2) is identified by IR. The IR spectrum of esters (3-9) show one sharp peak at wave number $v \quad 1754-1780 \mathrm{~cm}^{-1}$ corresponding to the ester $\mathrm{C}=\mathrm{O}$ group. The two peaks at $v$ 3286-1524-1544and $1346-1358 \mathrm{~cm}^{-1}$ are assigned to the asymmetric and symmetric stretching vibrations of the $\mathrm{NO}_{2}$ group respectively (Socrates, 1980). 
<smiles>[X]c1ccc(O)c([X])c1I</smiles>

10-13<smiles>[R]C(=O)Oc1ccc([Y])c([Z])c1[X]</smiles>

1-9
1. $\mathrm{X}=\mathrm{Z}=\mathrm{H}, \mathrm{Y}=\mathrm{NO}_{2}, \mathrm{R}=\mathrm{CH}_{3}$

2. $\mathrm{X}=\mathrm{NO}_{2}, \mathrm{Y}=\mathrm{Z}=\mathrm{H}, \mathrm{R}=\mathrm{CH}_{3}$

3. $\mathrm{X}=\mathrm{Z}=\mathrm{H}, \mathrm{Y}=\mathrm{NO}_{2}, \mathrm{R}=\mathrm{n}$-propyl

4. $\mathrm{X}=\mathrm{Z}=\mathrm{H}, \mathrm{Y}=\mathrm{NO}_{2}, \mathrm{R}=$ isopropyl

5. $\mathrm{X}=\mathrm{NO}_{2}, \mathrm{Y}=\mathrm{Z}=\mathrm{H}, \mathrm{R}=\mathrm{n}$-propyl

6. $\mathrm{X}=\mathrm{NO}_{2}, \mathrm{Y}=\mathrm{Z}=\mathrm{H}, \mathrm{R}=$ isopropyl

13. $\mathrm{X}=\mathrm{NO}_{2}, \mathrm{Y}=\mathrm{CF}_{3}, \mathrm{Z}=\mathrm{H}$

Reaction (1)
7. $\mathrm{X}=\mathrm{H}, \mathrm{Y}=\mathrm{NO}_{2}, \mathrm{Z}=\mathrm{CF}_{3}, \mathrm{R}=$ n-propyl
8. $\mathrm{X}=\mathrm{H}, \mathrm{Y}=\mathrm{NO}_{2}, \mathrm{Z}=\mathrm{CF}_{3}, \mathrm{R}=$ isopropyl
9. $\mathrm{X}=\mathrm{NO}_{2}, \mathrm{Y}=\mathrm{CF}_{3}, \mathrm{Z}=\mathrm{H}, \mathrm{R}=\mathrm{n}$-propyl
10. $X=Z=H, Y=N_{2}$
11. $X=\mathrm{NO}_{2}, Y=Z=\mathrm{H}$
12. $\mathrm{X}=\mathrm{H}, \mathrm{Y}=\mathrm{NO}_{2}, \mathrm{Z}=\mathrm{CF}_{3}$

The ${ }^{1} \mathrm{H}$ - NMR spectrum of $\mathbf{( 3 , 5}$ and7) containing n-propyl groupin $\mathrm{CH}_{3} \mathrm{OD}$ show triplet peak at $\delta$ 0.98-1.31ppm representing $\mathrm{CH}_{3}$ group, multiplet peak at $\delta 1.66-1.87 \mathrm{ppm}$ corresponding to $\mathrm{CH}_{2}$ group, triplet peak 2.53-2.64ppm corresponding to $\mathrm{CH}_{2}$ group. The aromatic protons of these esters positioned in the range 7.2-8.0ppm depending on the position and nature of $\mathrm{NO}_{2}$ - and $\mathrm{CF}_{3}$ substituents. Also, The ${ }^{1} \mathrm{H}$ NMR spectrum of (4,6 and 8) containing isopropyl group in $\mathrm{CH}_{3} \mathrm{OD}$ show multiplet peak at $\delta 2.8$-3.3ppm representing $\mathrm{CH}$ group and doublet peak at $\delta 1.34-1.7 \mathrm{ppm}$ corresponding to two methyl groups.

\subsection{Reaction Products.}

The mopholinolysis of substituted phenyl acetate, n-butyrate and isobutyrate (1 to 9) with morpholine in $90 \%$ Methanol-water mixed solvent proceeds exclusively through acyl-oxygen scission rather than aryl-oxygen scission as indicated from the identification of substituted phenoxide, reaction (2).
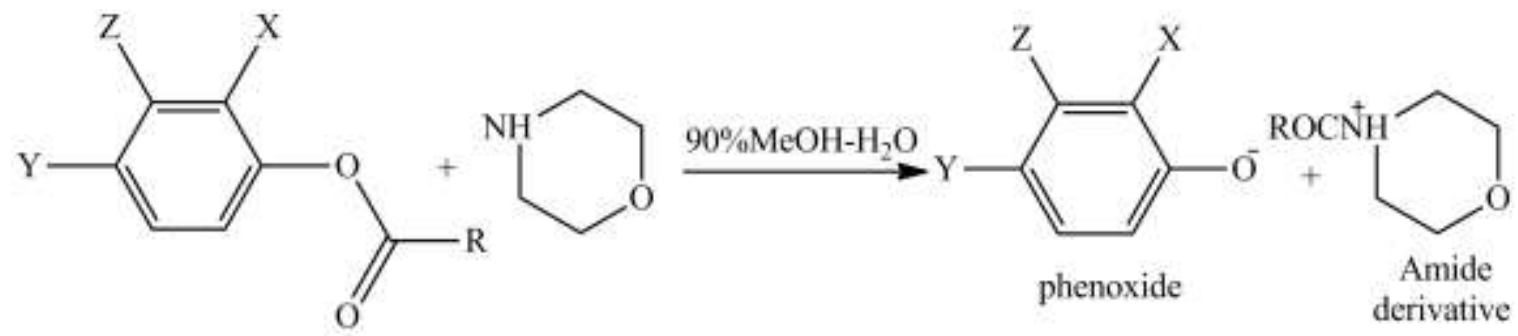

Reaction (2).

This is confirmed from the UV spectrophotometric matching of the known phenoxide derivatives with those obtained from reaction of compounds (1 to 9) with morpholine in $90 \%$ Methanol-water.

It was reported that the pka values of acetic $\left(\mathrm{pka}=4.756,4.800, \mathrm{n}\right.$-butyric $\left(\mathrm{pk}_{\mathrm{a}}=4.62,4.83\right)$ and isobutyric acids $(4.86,4.84)$ are of lower values than 2-nitro $(7.23,7.57,7.49)$, 4-nitro (pka = 7.15) and 4-nitro-3-trifluoromethyl phenols ( $\mathrm{pka}=6.0,6.30$ ) which means that the leaving group is the carboxylate ion. Actually, the observation of bands corresponding to aryloxide ions in the spectroscopic measurements indicates that the non-leaving group is OCOR and the leaving group is the -OAr one although the latter have higher pka values. This is explained by the resonance between the lone pair on the oxygen of the ester group and 2-nitro and 4-nitro in compounds (1 to 9) which creates double bond character between this oxygen atom and the nitrophenyl ring. This directs the attack of morpholine on the carbonyl group followed by acyl-oxygen fission rather than aryl-oxygen fission.

\subsection{Kinetic Study}

\subsubsection{Spectrophotometric Studies}

The kinetic studies were performed spectrophotometricallyby monitoring the formation of nitrophenoxide anions between 390nm and $415 \mathrm{~nm}$ for the reaction of (1 to 9) with morpholine. A representative full spectrum for the reaction of ester (8) with morpholine in $90 \%$ Methanol-water was measured spectrophotometrically by following the appearance of nitrophenoxide anions. 


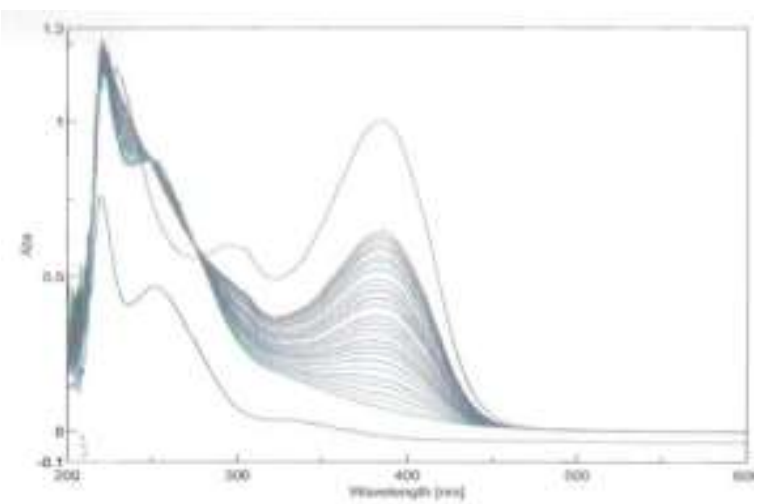

Figure 5. Full curve for the reaction of 4-nitro-3-trifluoromethyl phenyl isobutyrate(8) with morpholine (Mo) in 90\% Methanol-water at room temperature

The reactions of the esters (1-9) with morpholine obeyed pseudo-first-order rate constants $\left(k_{\text {obs }}\right)$ which were obtained from the slope of the linear plot of $\ln \left(\mathrm{A}_{\infty}-\mathrm{A}_{\mathrm{t}}\right)$ vs. time, Table.1. The linear plots of $\mathrm{k}_{\mathrm{obs}} v s$. [Mo], indicated that no third-order terms were detected, and no complications were found in the determination of $k_{\mathrm{obs}}$. This suggests that there is no base-catalysis and the contribution of $\mathrm{H}_{2} \mathrm{O}$ or noticeable side reactions are negligible. Thus, the overall reactions follow second order reaction. Second-order rate constants $\left(k_{\mathrm{A}}\right)$ were calculated from the slope of the linear plots of $\mathrm{k}_{\mathrm{obs}} v s$. [Mo],. Similar values of $\mathrm{k}_{\mathrm{A}}$ were obtained by dividing $\mathrm{k}_{\mathrm{obs}}$ by the corresponding morpholine concentration, table.2. Therefore these reactions obey a clean second-order rate law, Equations 2 and 3.

$$
\begin{aligned}
& \text { Rate }=\mathrm{k}_{\mathrm{obs}} \times[\text { Ester }] \\
& \mathrm{k}_{\mathrm{obs}}=\mathrm{k}_{\mathrm{A}} \times[\mathrm{Mo}]
\end{aligned}
$$

Table 1. Search for morpholine Catalysis. First order rate constants $k_{\text {obs }}$ and Second-order rate constants $k_{A}$ in

\begin{tabular}{|c|c|c|c|c|c|c|c|c|c|}
\hline \multicolumn{10}{|c|}{$k_{\mathrm{obs}} \times 10^{5} \mathrm{~s}^{-1}$} \\
\hline $\begin{array}{c}10^{3} \times[\text { Morpholine }] \\
\text { in mol. } 1^{-1} \\
\end{array}$ & 1 & 2 & 3 & 4 & 5 & 6 & 7 & 8 & 9 \\
\hline 1.0 & 3.49 & ---- & ---- & ---- & ---- & ---- & 23.00 & 11.78 & 34.50 \\
\hline 2.0 & 7.95 & ---- & ---- & ---- & ---- & ---- & 26.90 & 19.30 & 53.70 \\
\hline 3.0 & 15.00 & ---- & ---- & ---- & ---- & ---- & 72.90 & 28.80 & 88.30 \\
\hline 4.0 & 28.00 & ---- & ---- & ---- & ---- & ---- & 96.00 & 36.00 & 111.00 \\
\hline 5.0 & ---- & 23.00 & ---- & ---- & ---- & ---- & 11.50 & ---- & 138.00 \\
\hline 5.5 & ---- & 29.60 & ---- & ---- & ---- & ---- & ---- & ---- & ---- \\
\hline 6.0 & 38.40 & 32.90 & ---- & ---- & ---- & ---- & 15.30 & 43.20 & ---- \\
\hline 6.5 & ---- & 37.10 & ---- & ---- & ---- & ---- & ---- & ---- & ---- \\
\hline 7.0 & ---- & 38.40 & ---- & ---- & ---- & ---- & ---- & ---- & ---- \\
\hline 7.5 & ---- & 42.20 & ---- & ---- & ---- & ---- & ---- & ---- & ---- \\
\hline 10.0 & ---- & ---- & 18.80 & 12.70 & ---- & ---- & ---- & ---- & ---- \\
\hline 15.0 & ---- & ---- & 24.60 & 20.20 & ---- & ---- & ---- & ---- & ---- \\
\hline 20.0 & ---- & ---- & 33.50 & 23.80 & ---- & ---- & ---- & ---- & ---- \\
\hline 25.0 & ---- & ---- & 42.70 & 37.00 & ---- & ---- & ---- & ---- & ---- \\
\hline 30.0 & ---- & ---- & 52.80 & 45.00 & ---- & ---- & ---- & ---- & ---- \\
\hline 35.0 & ---- & ---- & 64.5 & 55.10 & ---- & ---- & ---- & ---- & ---- \\
\hline 50.0 & ---- & ---- & ---- & ---- & & 5.00 & ---- & ---- & ---- \\
\hline 100.0 & ---- & ---- & ---- & ---- & 173.00 & 10.30 & ---- & ---- & ---- \\
\hline 150.0 & ---- & ---- & ---- & ---- & 203.00 & 14.00 & ---- & ---- & ---- \\
\hline 200.0 & ---- & ---- & ---- & ---- & 234.00 & 20.40 & ---- & ---- & ---- \\
\hline 250.0 & ---- & ---- & ---- & ---- & 280.00 & 26.40 & ---- & ---- & ---- \\
\hline 300.0 & ---- & ---- & ---- & ---- & 345.00 & 32.00 & ---- & ---- & ---- \\
\hline $10^{2} \mathrm{k}_{\mathrm{A}} 1 . \mathrm{mol}^{-1} \mathrm{~s}^{-1}$ & 8.10 & 7.20 & 1.84 & 1.70 & 0.800 & 0.110 & 26.00 & 6.40 & 26.40 \\
\hline
\end{tabular}
reaction of esters ( 1 to 9 ) with morpholine in $90 \%$ Methanol-water at $25^{\circ} \mathrm{C}$. 
Table 2. The second order rate constants $\mathrm{k}_{\mathrm{A}}\left(1 \cdot \mathrm{mol}^{-1} \mathrm{~s}^{-1}\right)$ and activation parameter values for the morpholinolysis of compounds (1 to 9) in $90 \%$ Methanol-water at different temperatures $\left(25-45^{\circ} \mathrm{C}\right)$.

\begin{tabular}{|c|c|c|c|c|c|c|c|c|c|}
\hline \multirow[b]{2}{*}{$\mathbf{t}^{0} \mathrm{C}$} & \multicolumn{9}{|c|}{$10^{2} k_{A} 1 . m o l^{-1} \cdot s^{-1}$} \\
\hline & 1 & 2 & 3 & 4 & 5 & 6 & 7 & 8 & 9 \\
\hline 25 & 8.10 & 7.20 & 1.84 & 1.70 & 0.80 & 0.11 & 26.00 & 6.40 & 26.40 \\
\hline 30 & 9.60 & 9.30 & 2.30 & 1.92 & 0.88 & 0.12 & 27.60 & 9.90 & 49.80 \\
\hline 35 & 11.20 & 10.40 & 2.98 & 2.47 & 0.95 & 0.14 & 31.50 & 12.8 & 72.90 \\
\hline 40 & 14.50 & 12.20 & 4.00 & 3.06 & 1.17 & 0.16 & 36.40 & 14.1 & 103.60 \\
\hline 45 & 15.30 & 13.00 & 5.44 & 3.64 & 1.50 & 0.20 & 41.00 & 18.2 & 149.69 \\
\hline$\Delta \mathbf{H}^{\#}\left(\mathrm{~kJ} \cdot \mathrm{mol}^{-1}\right)$ & 24.17 & 20.47 & 40.71 & 29.03 & 26.75 & 21.54 & 16.31 & 8.57 & 63.78 \\
\hline 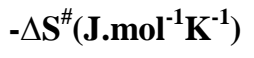 & 184.91 & 197.52 & 142.20 & 181.69 & 200.95 & 229.98 & 201.83 & 234.44 & 40.70 \\
\hline$\Delta \mathbf{G}^{\#}\left(\mathrm{~kJ} \cdot \mathrm{mol}^{-1}\right)$ & 81.12 & 81.31 & 84.51 & 84.99 & 87.44 & 92.38 & 78.47 & 80.78 & 76.32 \\
\hline 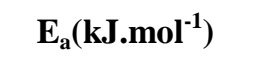 & 26.73 & 23.03 & 43.27 & 31.59 & 24.34 & 24.11 & 18.87 & 11.13 & 66.34 \\
\hline
\end{tabular}

\subsubsection{Reaction of Compounds ( 1 and 2) with Morpholine in 90\% Methanol-water}

It has been proposed that acyl-transfer reactions for esters and carbamates with nucleophiles proceed via either a concerted, a stepwise or a substitution via elimination-addition mechanism, depending on the nature of the nucleophile, the substrate, its leaving group and the solvents involved (Khattab, Hassan, Hamed, Albericio\&El-Faham, 2010).

The values of $\Delta \mathrm{H}^{\#}$ and $\Delta \mathrm{S}^{\#}$ for the reaction of morpholine with esters $\left(\begin{array}{l}1 \\ \&\end{array}\right)$ are respectively obtained from the Arrhenius plots. Table. 2 shows low positive $\Delta \mathrm{H}^{\#}$ and large negative $\Delta \mathrm{S}^{\#}$ values indicating a rigid transition state or methanol molecules are greatly participate in the activated complex. This difference in rate constants as well as the $\Delta \mathrm{H}^{\#}$ and $\Delta \mathrm{S}^{\#}$ values are due to the degree of bond formation between the amine nucleophile and the carbonyl carbon. Shawali et al., (Shawali, Harhash, Hassanee, Alkaaabi, 1986) proposed a stepwise mechanism with rate limiting breakdown of a tetrahedral intermediate $\mathrm{T}^{ \pm}$for the reaction of ester with amine. The stepwise mechanism (i) could involve two reaction pathways, an overall second-order, $\mathrm{k}_{2}$, (uncatalyzed reaction), and an overall third-order, $\mathrm{k}_{3}$ (the reaction is catalyzed by the amine) which is reject in our reaction. Alternatively, the morpholinolysis of esters ( 1 \& 2) may proceed via a concerted mechanism involving transition state $\mathrm{T}^{ \pm}$concerted. (Castro, Aguayo, Bessolo, Santos, 2005).

The $k_{\mathrm{A}}$ values for the morpholinolysis of reactions of esters $(1 \& \mathbf{2})$, with morpholine at temperatures $25-45^{\circ} \mathrm{C}$ are summarized in Table.2.

Our results could favor a concerted mechanism for the reaction of ester (1) with morpholine, (Scheme.1, pathway a), and a stepwise mechanism for the reaction of ester (2) with morpholine, (Scheme.1, pathway b) one can suggest $\mathrm{T}^{ \pm}$concerted for a concerted mechanism both the attack of the nucleophile and the departure of the leaving group are partially advanced. On the other hand, the reactions have been suggested to proceed through a zwitterionic tetrahedral intermediate with its formation or breakdown being the RDS (Um, Park, Fujio, Mishima, Tsuno, 2007). This suggestion might be consistent with observation that the rate constant of ester $\left(\mathbf{1}, 4-\mathrm{NO}_{2}\right)$ is higher than ester $\left(\mathbf{2}, 2-\mathrm{NO}_{2}\right)$ while the enthalpy of activation for the reaction of ester $(\mathbf{1})$ is higher than this ofester (2). This can be used as an evidence for the different pathways of the nucleophillic acyl substitution (Um, Park ,2008).This previous concept is rejected because a $\Delta \mathrm{H}^{\#}$ difference of $3.5 \mathrm{KJ} / \mathrm{mole}$ is hardly enough to unambiguouly favor one pathway. Also, entropy data is virtually ignored. 


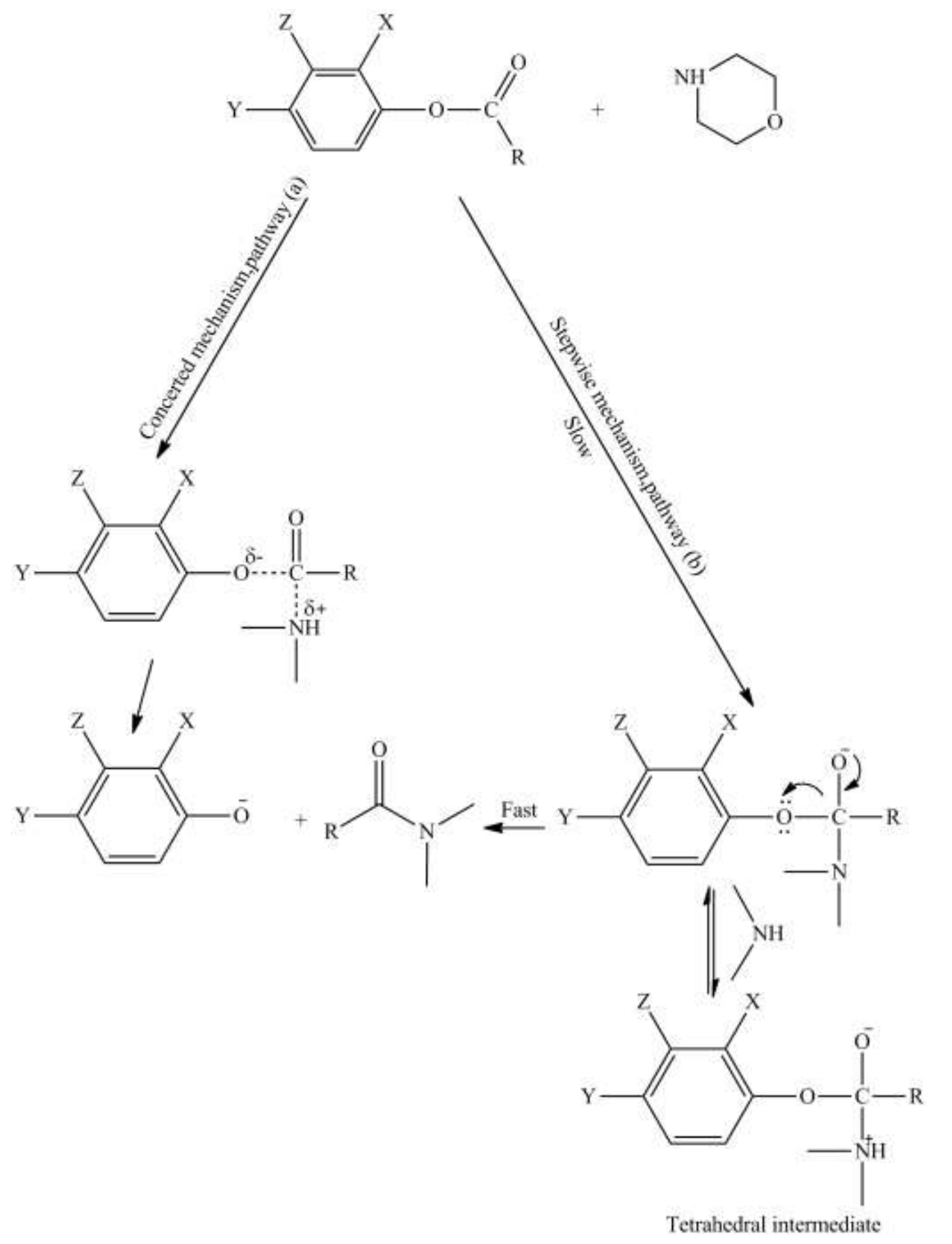

Scheme 1

Accordingly, the previous results are possible when the reactions of esters $\mathbf{1}$ and $\mathbf{2}$ proceed through a stepwise mechanism with a change in the position of the rate-determining step, Scheme.1. The first step of the reaction is the addition of an N-H bond from Mo molecule to the carbonyl double bond in nitrophenyl acetate $(\mathbf{1} \& \mathbf{2})$ and formation of a tetrahedral intermediate. This addition takes place through transition state TS1 (Figure 6). The second step of the reaction is the conversion of the tetrahedral intermediate into morpholinolysis products through the transition state TS2 (Figure 6). 


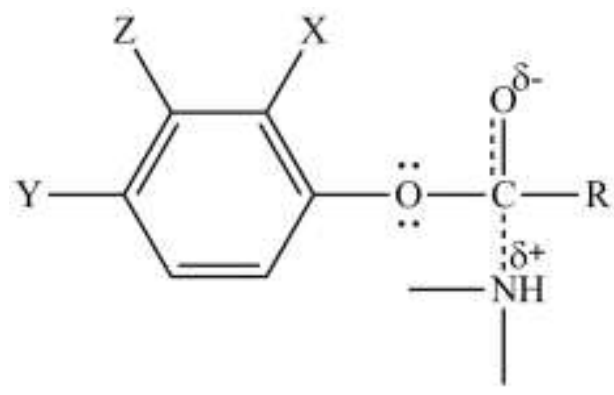

TS1

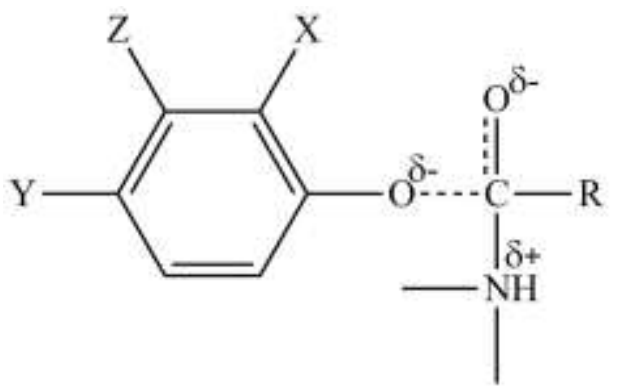

TS2

Figure 6. Two transition states

It was reported that the two transition states TS1 and TS2 have very similar energies and the nucleophilic attack is the rate determining step. The major structural difference between the two TS's is the degree of bond formation between the amine nucleophile and the carbonyl carbon (i.e., bond formation is advanced partially in $\mathrm{TS}_{1}$ but fully in $\mathrm{TS}_{2}$ ). Thus, one might suggest that $\mathrm{TS}_{1}$ is less ordered than $\mathrm{TS}_{2}$. This feature can be associated with different stabilities of nitrophenoxides as leaving groups as well as the structure of the non-leaving carboxylate group.

Table 2: Shows that

(i) The reactions of esters $(\mathbf{3}, \mathbf{5}, \mathbf{7}$ and 9) with n-propyl ester group and (4, 6 and 8) with isopropyl ester group and Mo are similar to the previously discussed for the reaction for esters $(\mathbf{1} \& \mathbf{2})$ respectively. Esters with higher rate constants show higher enthalpy of activations and less negative entropy values.

(ii) The second-order rate constants $\left(\mathrm{k}_{\mathrm{A}} 1 . \mathrm{mol}^{-1} \mathrm{~s}^{-1}\right)$ for the reactions of esters (3 to 9) with Mo increased with increasing temperature from 25 to $45^{\circ} \mathrm{C}$.

(iii) The reactivity of the esters ( 1 to 9) towards Mo increases as the basicity of the leaving group decrease i.e. rate constant ratio $\mathrm{k}_{\mathrm{A}}(7) / \mathrm{k}_{\mathrm{A}}(3)$ is $14.13-7.53$ and $\mathrm{k}_{\mathrm{A}}(8) / \mathrm{k}_{\mathrm{A}}(4)$ is $3.23-1.21$ as the pka of the conjugate base of the 4-nitro-3-trifluoromethyl phenol(7) increases from 6.0-6.3 $\left(\mathrm{H}_{2} \mathrm{O}\right)$ to $7.15\left(\mathrm{H}_{2} \mathrm{O}\right)$ for 4-nitro-phenol at $25^{\circ} \mathrm{C}$. This is not attributed to the difference in acidity between parent acids: acetic acid, n-butyric acid and isobutyric acid because these acids have comparable pka values. Therefore, one can propose that the replacement of methyl by propyl or isopropyl in the non-leaving group and the pka of the leaving group influences the reactivity of the titled esters. In other words, the difference in the $k_{\mathrm{A}}$ between the two series of reactions is small due to the small difference between the leaving group basicity and when the leaving group basicity is the same, the reaction is from moderate to small dependent on the ester alkyl group except compounds $(\mathbf{7}, \mathbf{8})$.

In general, the previous results are possible when the reactions of esters 1-9 proceed through a stepwise mechanism with a change in position of the rate-determining step, Scheme.1. Arrhenius plots exhibit good linear correlations indicating that the activation parameters calculated from the slope and intercept are accurate, Table. 2 shows that the reaction of $(\mathbf{3}, \mathbf{5}, \mathbf{7})$ results in approximately $11.68-5.21 \mathrm{~kJ} / \mathrm{mol}$ higher $\Delta \mathrm{H}^{\#}$ than that of $(\mathbf{4 , 6 , 8 )}$ although $(\mathbf{3}, \mathbf{5}, \mathbf{7})$ are more reactive than the corresponding esters $(\mathbf{4 , 6}, \mathbf{8})$ toward morpholine. However, this is expected on the basis of the structural difference between TS1 and TS2. One might expect that the energy released by formation of the $\mathrm{C}-\mathrm{N}$ bond is smaller for the reaction of esters $(\mathbf{1 , 3 , 5 , 7 )}$ than for those of $(\mathbf{2}, \mathbf{4 , 6 , 8 )}$ while the energy needed to break the C-OAr bond in the two TS is the opposite. This presumably accounts for the fact that the former reaction exhibits larger $\Delta \mathrm{H}^{\#}$ than the latter reaction.

It is also noted that the reactions of esters $(\mathbf{1}, \mathbf{3}, \mathbf{5}, \mathbf{7})$ exhibit $9.63-32.61 \mathrm{~J}^{-\mathrm{mol}^{-}} . \mathrm{K}^{-1}$ less negative $\Delta \mathrm{S}^{\#}$ than those of $(2,4,6,8)$ indicating that TS1 is less ordered than TS2. Thus, one can consider TS1 as the TS structure for the reaction of $(\mathbf{1}, \mathbf{3}, \mathbf{5}, \mathbf{7})$ and TS2 as the TS structure for the reactions $(\mathbf{2}, \mathbf{4}, \mathbf{6 , 8})$.

It is found that the plot of $\log \mathrm{k}_{\mathrm{A}}\left(25^{\circ} \mathrm{C}\right)$ versus $\log \mathrm{k}_{\mathrm{A}}\left(45^{\circ} \mathrm{C}\right)$ for the reactions of esters (1-9) with morpholine gives scattered points with poor correlation, while such plot for the same reaction of series $(\mathbf{1}, \mathbf{3}, \mathbf{5}, \mathbf{7})$ and $(\mathbf{2}, \mathbf{4}$, 6, 8) gave good correlations. Similarly, the plot of $\Delta H^{\#}$ versus $\Delta S^{\#}$ for each series improves the correlation in contrast to the scattered points when all esters are used in the correlation. These observations are in agreement with the suggested stepwise mechanism with the transition states TS1 and TS2 for esters $(\mathbf{1 , 3} \mathbf{3}, \mathbf{5}, \mathbf{7})$ and esters $(\mathbf{2}$, $4,6,8)$ respectively.

The relatively higher $\mathrm{k}_{\mathrm{A}}$ values for the reaction of ester (9) with Mo than for ester (7) that contains the same substituents $-\mathrm{CF}_{3}$ and $-\mathrm{NO}_{2}$ as ester (9) but in different positions is presumably due to the $-\mathrm{CF}_{3}$ substituent in 
ester (7). The $3-\mathrm{CF}_{3}$ substituent slightly inhibits the effect of $4-\mathrm{NO}_{2}$ to stabilize the phenoxide anion leaving group, while kinetic data indicated that this steric effect is diminished in ester (9) that contains $2-\mathrm{CF}_{3}$ substituent..

Table. 2, reveals that $\mathrm{k}_{\mathrm{A}}$ for esters $(\mathbf{7}, \mathbf{9})$ which contain $\mathrm{n}$-propyl ester group are larger than that of esters $(\mathbf{8})$ which contains isopropyl ester group. This is due to the crowding affect of isopropyl group on their transition states. The comparison between the $\mathrm{k}_{\mathrm{A}}$ values for the isopropyl ester $(\mathbf{8})$ which contains $-\mathrm{CF}_{3}$ and $-\mathrm{NO}_{2}$ and the isopropyl ester (4) containing only $4-\mathrm{NO}_{2}$ group shows that the former is greater than the latter by approximately 5.16-3.23 times. This may be due to the presence of the electron withdrawing group $-\mathrm{CF}_{3}$ which increases the electrophillicity of the carbonyl carbon reaction center.

\section{Conclusion}

The rate constants of the reaction of esters (1-9) with Mo, activation parameters and the correlation between $\log$ $\mathrm{k}_{\mathrm{A}(25)}$ versus $\log \mathrm{k}_{\mathrm{A}(45)}$ indicates that esters follow stepwise mechanism with change in the position of the slow step. It was concluded that esters $(\mathbf{1}, \mathbf{3}, \mathbf{5}, \mathbf{7})$ undergo slow attack of Mo to form tetrahedral intermediate via TS1 while esters $(\mathbf{2}, \mathbf{4}, \mathbf{6}, \mathbf{8})$ passes through stepwise process in which the departure of the leaving group via TS2 is the controlling step. Also, the presence of $-\mathrm{CF}_{3}$ substituent in ester (7) inhibit the effect of 4- $\mathrm{NO}_{2}$ to stabilize the phenoxide anion leaving group. Kinetic data indicated the steric effect is diminished for the reaction of ester (9) and the bulkness of isopropyl group leads to lower $\mathrm{k}_{\mathrm{A}}$ values.

Future studies will be made to substantiate the mechanism such as (i) the use of more substrates with different electron withdrawing group and electron donating groups at different positions. (ii) apply computational quantum chemistry in studying the mechanism of morphinolysis of the titled esters.

\section{References}

Bernasconi, C. F. (1986). Techniques of Organic Chemistry (4th ed.). Wiley: New York, 6.

Brogden, R. N., \& Clissold, S. P. (1989). Drugs, 38, 185. http://dx.doi.org/10.2165/00003495-198938020-00003

Buncel, E., Chuaqui, C., Forsythe, P., Mahoney, S., Raoult, A., \& Willtshir, J. F. Perkin II. (1975). J. Chem. Soc, 478.

Castro, E. A., Aguayo, R., Bessolo, J., \& Santos, J. G. (2005). J. Org. Chem, 70, 7788. http://dx.doi.org/10.1021/jo051052f

El-Hegazy, F. M., Abdel-Fattah, S. Z., Hamed, E. A., \& Sharaf, S. M. (2000). J. Phys. Org. Chem, 13, 549. http://dx.doi.org/10.1002/1099-1395(200009)13:9<549::AID-POC297>3.0.CO;2-5

Fathalla, M. F., Kassem, T. S., \& Hamed, E. A. (2009). Indian J. Chem, Sect, 47A, 1348.

Feuer, H., \& Patai, S. (Eds.). (1969). The Chemistry of the Nitro and Nitroso Groups, Wiley-Inter science, New York.

Guanti, G., Dell'Erba, C., \& Pero, F. (1975). Chem. Commun, 55, 823. http://dx.doi.org/10.1039/c39750000823

Guanti, G., Dell'Erba, Pero, F., \& Leandri, G. (1977). J. Chem. Soc, Perkin II. 966. http://dx.doi.org/10.1039/p29770000966

Hamed, E. A. (1997). Int. J. Chem. Kinet, 29, 599. http://dx.doi.org/10.1002/(SICI)1097-4601(1997)29:8<599::AID-KIN5>3.0.CO;2-P

Hamed, E. A. (2011). Int. J. Chem. Kinet, 29, 515. http://dx.doi.org/10.1002/(SICI)1097-4601(1997)29:7<515::AID-KIN5>3.0.CO;2-X

Hamed, E. A., El-Bardan, A. A., Saad, G. A., Gohar, G. A., \& Hassan, G. M. (1997). J. Chem. Soc., Perkin Trans, 2, 2415. http://dx.doi.org/10.1039/a701902e

Ibrahim, M. F., El-atawy, M. A., El-Sadany, S. K., \& Hamed, E. A. (2011). Journal of Molecular Structure, 1006, 303-311. http://dx.doi.org/10.1016/j.molstruc.2011.09.024

Ibrahim, M. F., El-atawy, M. A., El-Sadany, S. K., Hamed, E. A. (2013). Int. J. Chem. Kinet, 45, 551-559. http://dx.doi.org/10.1002/kin.20779

Jonler, M., Riehmann, M., \& Bruskewitz, R.C. (1994). “Drugs”, 47, 66. http://dx.doi.org/10.2165/00003495-199447010-00005

Khattab, N. S., Hassan, Y. S., Hamed, A. E., Albericio, F., \& El-Faham, A. (2010). Bull. Korean Chem. Soc, 31(1), 75. http://dx.doi.org/10.5012/bkcs.2010.31.01.075 
Khattab, S. N., Hassan, S. Y., Hamed, E. A., Albericio. F., \& El-Faham, A. (2010). Bull. Korean Chem. Soc.

Kirby, A. J., \& Jencks, W P. (1965). J. Am. Chem. Soc, 87, 3209. http://dx.doi.org/10.1021/ja01092a036

Kirkien-Konasiewicz, A., \& Maccoll, A. (1964). J. Chem. Soc, 1267-1274. http://dx.doi.org/10.1039/jr9640001267

Kirsch, J. F., \& Clewell, W. A., \& Simon, A. (1968). J. Org. Chem, 33, 127. http://dx.doi.org/10.1021/jo01265a023

Lee, Jong-Pal., Yoon, Ji-Hui \& Um, Ik-Hwan. (1999). Bull. Korean Chem. Soc, $20,7$.

Menger, F. M., \& Glass, L. E. (1974). J. Org. Chem, 39, 2469-2470. http://dx.doi.org/10.1021/jo00930a052

Shawali, A. S., Harhash, A., Hassanee, H. M., \& Alkaaabi, S. S. (1986). J. Org. Chem, 51, 3498. http://dx.doi.org/10.1021/jo00368a020

Socrates, G. (1980). Infrared Characteristic Group Frequencies, John Wiley \& Sons.

Um, I. H., \& Park Y. M. (2008). Bull. Korean Chem. Soc, 29(3), 575. http://dx.doi.org/10.5012/bkcs.2008.29.3.575

Um, I. H., Min, J. S., Ahn, J. A., \& Hahn, H. J. (2000). J. Org. Chem, 65, 5659. http://dx.doi.org/10.1021/jo000482x

Um, I. H., Park, Y. M., Fujio, M., Mishima, M., \& Tsuno, Y. (2007). J. Org. Chem, 72, 4816. http://dx.doi.org/10.1021/jo0705061

Um, Ik-Hwan., Lee, Eun-Ju., \& Lee, \& Jong-Pal. (2002). Bull. Korean Chem. Soc, 23(3), 381. http://dx.doi.org/10.5012/bkcs.2002.23.3.381

\section{Copyrights}

Copyright for this article is retained by the author(s), with first publication rights granted to the journal.

This is an open-access article distributed under the terms and conditions of the Creative Commons Attribution license (http://creativecommons.org/licenses/by/3.0/). 